\title{
Análise da eficiência das indústrias de açúcar e álcool com a análise envoltória de dados
}

Este artigo teve como objetivo determinar a eficiência produtiva das indústrias sucroalcooleiras situadas no estado de Mato Grosso do Sul (MS) e verificar quais indústrias eficientes podem ser referências às ineficientes. Utilizou-se de metodologia quantitativa com dados secundários, obtidos de organismos oficiais, tais como: Instituto Brasileiro de Geografia e Estatística (IBGE) e União da Indústria de Cana-de-Açúcar (UNICA), com uso da Análise Envoltória de Dados (DEA - sigla em inglês de Data Envelopment Analysis) ferramenta não paramétrica que avalia a eficiência técnica relativa de unidades produtivas. Os anos analisados foram 2000, 2005, 2010 e 2015, com um insumo (cana-de-açúcar) e dois produtos (açúcar e etanol). Esses períodos foram escolhidos seguindo preceitos do IBGE, com fins de determinar se as empresas se encontram em comparação a períodos passados e, também, em razão de apurar as (in) eficiências no decorrer dos períodos nas Unidades Tomadoras de Decisão (DMU, da sigla em inglês Decision Making Units). O modelo DEA-CCR com orientação de entrada foi escolhido para obter a classificação das indústrias de cana-de-açúcar. Os resultados mostraram que as empresas instaladas apresentaram de média a alta eficiência no uso de cana-deaçúcar. As conclusões apontaram que a eficiência média caiu entre os períodos analisados, no entanto, nenhuma das unidades apresentou baixa eficiência, nem mesmo aquelas que estavam paralisando as atividades.

Palavras-chave: Produção de açúcar; Produção de etanol; Eficiência produtiva.

\section{Analysis of the efficiency of the sugar and alcohol industries with data envelopment analysis}

\begin{abstract}
This article aimed to determine the productive efficiency of sugar and alcohol industries located in the state of Mato Grosso do Sul (MS) and to verify which efficient industries can be references to inefficient ones. A quantitative methodology was used with secondary data, obtained from official organizations, such as Brazilian Institute of Geography and Statistics (IBGE) and Sugarcane Industry Union (UNICA), using Data Envelopment Analysis (DEA) non-parametric tool that assesses the relative technical efficiency of production units. The years analyzed were 2000, 2005, 2010 and 2015, with one input (sugar cane) and two products (sugar and ethanol). These periods were chosen following IBGE precepts, in order to determine if the companies are compared to past periods and because of the (in) efficiencies over the periods in the Decision Making Units (DMU). The DEA-CCR model with input orientation was chosen to obtain the sugarcane industries classification. The results showed that the installed companies presented medium to high efficiency in the use of sugarcane. The conclusions showed that the average efficiency decreased between the analyzed periods; however, none of the units presented low efficiency, not even those that were paralyzing the activities.
\end{abstract}

Keywords: Sugar production; Ethanol production; Productive efficiency.

Topic: Desenvolvimento, Sustentabilidade e Meio Ambiente

Reviewed anonymously in the process of blind peer.
Received: 09/12/2019

Approved: 19/01/2020
Valdir Antonio Balbino (iD)

Universidade Estadual de Mato Grosso do Sul, Brasil http://lattes.cnpq.br/6614413798718337 http://orcid.org/0000-0002-8972-8465 contvaldir@hotmail.com

Celso Correia de Souza (iD

Universidade Anhanguera, Brasil

http://lattes.cnpq.br/2881392515816773

http://orcid.org/0000-0002-2689-8264

csouza939@gmail.com

Daniel Massen Frainer (i)

Universidade Estadual de Mato Grosso do Sul, Brasil

http://lattes.cnpq.br/6910455102814572

http://orcid.org/0000-0003-0813-214X

danielfrainer@gmail.com
Referencing this:

BALBINO, V. A.; SOUZA, C. C.; FRAINER, D. M.. Análise da eficiência das indústrias de açúcar e álcool com a análise envoltória de dados. Revista Ibero Americana de Ciências Ambientais, v.11, n.1, p.351361, 2020. DOI: http://doi.org/10.6008/CBPC2179$\underline{6858.2020 .001 .0032}$ 


\section{INTRODUÇÃO}

As ações antrópicas sempre causaram efeitos adversos sobre o meio ambiente. Mas a partir de meados do século XX, com o aumento desenfreado da população humana, iniciou-se a preocupação de diagnosticar esses efeitos adversos sobre o meio ambiente. A busca de soluções acabou provocando a participação estatal, bem como, a iniciativa privada de forma mais proativa. Assim, por meio de avanços tecnológicos e novas formas de produção, fertilização, criação de sementes geneticamente modificadas, adaptáveis a climas e solos, agrotóxicos e adubos químicos, entre outros, se tem conseguido manter níveis satisfatórios de produção de alimentos (COELHO, 2007).

Essas novas formas produtivas têm procurado considerar os custos ambientais e sociais no processo, como forma de obtenção de desenvolvimento sustentável. Nesse sentido, a eficiência produtiva vem sendo buscada na intenção tanto de reduzir insumos e custos como para mitigar os efeitos adversos dos resíduos sobre o meio ambiente (NOGUEIRA et al., 2013). Essa eficiência pode ser medida em termos de redução de recursos com alta produtividade, minimizando assim, os descartes de resíduos e promovendo ao mesmo tempo crescimento econômico com equilíbrio ambiental e melhoria no bem-estar social (SOUZA, 2009).

Uma das formas de se medir a eficiência é por meio da Análise Envoltória de Dados (DEA em inglês). A DEA tem por finalidade verificar quais unidades produtivas são mais eficientes, seja no uso dos recursos que utilizam ou nos produtos que produzam. Essa ferramenta matemática não paramétrica tem sido utilizada, em decorrência dos avanços tecnológicos, em estudos e produções científicas (MEZA et al., 2007). Ela permite o uso em conjunto de vários inputs (insumos) e outputs (produtos), para traçar fronteiras virtuais de eficiência, tanto em razão de insumos quanto de produtos (SALGADO JUNIOR et al., 2009).

A DEA, desenvolvida por Charnes et al. (1978), utiliza-se de programação linear para avaliar a eficiência de várias DMU's, que ocupam em seus processos produtivos os mesmos tipos de recursos (inputs) e geram produtos semelhantes (outputs). A DEA tem sido muito utilizada para avaliar a eficiência das empresas nos mais variados ramos de atividades, e no agronegócio não é diferente. Em relação à canavicultura, alguns exemplos de estudos fora do Brasil são: Lestari et al. (2016), Ahmad et al. (2018) e no Brasil: Salgado Junior et al. (2009), Brunozi Júnior et al. (2012), Salgado Junior et al. (2014); entre outros.

O setor canavieiro no Brasil, em razão dos avanços tecnológicos a partir da década de 1950, vem se destacando na produção de energia por meio da biomassa, a qual se glorifica por ser detentora de energia renovável, portanto, mais benéfica que os combustíveis fósseis. O maior estado produtor de cana de açúcar é São Paulo, no entanto, o estado de Mato Grosso do Sul vem se destacando nessa atividade entre os maiores estados brasileiros. Portanto, algumas questões se apresentam: As usinas de açúcar e álcool instaladas em MS são eficientes no uso dos insumos que utilizam? Quais usinas eficientes em MS podem servir de referências às usinas ineficientes? É uma atividade sustentável?.

Diante das questões formuladas, a pesquisa tem como objetivo determinar as eficiências produtivas das usinas sucroalcooleiras de MS, verificando quais delas podem servir como referências às não eficientes a fim de torna-las eficientes (benchmarking) e; efetuar reflexões sobre a sustentabilidade das usinas nos 
resíduos descartados. Essa pesquisa converge, ainda para que sejam repensadas as políticas públicas para o desenvolvimento regional e para a gestão ambiental do estado de MS.

\section{METODOLOGIA}

Foi aplicada neste estudo a estatística descritiva e a técnica de Análise Envoltória de Dados (Data Envelopment Analysis - DEA), que tem por finalidade classificar as usinas sucroalcooleiras de MS em níveis da eficiência. Cada unidade será denominada de unidade tomadora de decisão (Decision Making Units DMU) (CHARNES et al., 1994; CASADO, 2007; MEZA et al., 2007).

Utilizou-se da estatística descritiva para determinar os coeficientes de variação, as médias, os desvios padrão, os valores mínimos e máximos de produção da cana-de-açúcar, de açúcar e de etanol, em cada ano analisado. A eficiência é um conceito relativo, comparando o que foi produzido, dado os recursos disponíveis, com o que poderia ter sido produzido com os mesmos recursos. Assim, surge a fronteira de eficiência de produção, representada pelas DMU's que conseguirem minimizar o uso dos inputs (insumos) na produção de outputs (produtos) (MACEDO et al., 2007).

Existem dois modelos básicos de DEA para análise: O CCR e o BCC. A primeira data de 1978, o qual constrói uma superfície linear por partes, não paramétrica, envolvendo os dados. Trabalha com retornos constantes de escala, isto é, qualquer variação nas entradas (inputs) produz variação proporcional nas saídas (outputs) (CHARNES et al.,1978). O segundo modelo, desenvolvido em 1984 é de retornos variáveis de escala (Variable Returns to Scale - VRS). Esse modelo é mais benevolente que o primeiro, em termos de eficiência (BANKER et al., 1984).

Nesse sentido foi escolhido modelo DEA-CCR de retornos constantes de escala, no qual foi utilizado um insumo e dois produtos. Como insumo: a produção de cana-de-açúcar; como produtos: 1) a produção de açúcar e 2) a produção de etanol. Para a aplicação dos modelos básicos da técnica DEA existem alguns critérios a serem seguidos para não inviabilizar os resultados, quais sejam: as atividades devem ser de mesmo segmento; utilizarem-se de recursos semelhantes e produzirem mesmo tipo de produtos; o número de unidades tomadoras de decisão (Decision Making Units - DMU's) não podem ser inferiores ao resultado da multiplicação dos inputs pelos outputs (GOMES et al., 2012), no entanto, Wagner et al. (2007) preconizam utilizar quantidade de variáveis que sejam no máximo um terço das DMU's.

Assim, neste trabalho foi utilizado um input e dois outputs que dá um produto de dois, com oito DMU's no ano de 2000 que está de acordo com Gomes et al. (2012), com pequena diferença ao um terço preconizado por Wagner et al. (2007). No entanto, nos demais anos analisados (2005, 2010 e 2015), as duas opções estão completamente adequadas ao modelo.

Foi escolhida a análise orientada a insumos (inputs). Essa orientação minimiza os insumos, mantendo fixas as quantidades de produtos (MEZA et al., 2007; MACEDO et al., 2007). Isso quer dizer que se busca a produção de açúcar e álcool para atender a demanda do mercado com utilização mínima de cana-de-açúcar. Ou seja, a empresa que utilizar menos cana-de-açúcar e obter a maior quantidade possível de produtos é a mais eficiente. Essa escolha assumiu que, ao se minimizar a quantidade de cana-de-açúcar disponível, se 
consegue, também, minimizar o consumo de outros recursos escassos e, consequentemente, a redução de resíduos líquidos (a vinhaça) e sólidos (torta de filtro) altamente poluidores do meio ambiente.

Foi utilizado o Sistema Integrado de Apoio à Decisão (SIAD) versão 3.0 para obtenção dos resultados conforme Meza et al. (2005), para verificar a eficiência operacional das usinas de açúcar e álcool no estado de Mato Grosso do Sul, nos anos de 2000, 2005, 2010 e 2015. Esses períodos foram escolhidos seguindo preceitos do IBGE, e em razão de apurar as (in) eficiências no decorrer do tempo e efetuar ao final um escore das DMU's. Assim, o modelo DEA-CCR primal pode ser apresentado pela equação 1.

$$
\begin{aligned}
& \operatorname{Max} H_{0}=\sum_{j=1}^{s} u_{j} y_{j 0} \\
& \text { Sujeito a: } \\
& \left\{\begin{array}{l}
\sum_{i=1}^{r} v_{i} x_{i 0}=1 \\
\sum_{j=1}^{s} u_{j} y_{j k}-\sum_{i=1}^{r} v_{i} x_{i k} \leq 0
\end{array}\right. \\
& \forall i, j, k(i=1,2, \cdots, r ; j=1,2, \cdots, s ; k=1,2, \cdots, n) \\
& \text { Em que: } \mathrm{H}_{0}=\text { eficiência da } \mathrm{DMU}_{0} \text {; } \\
& r=\text { quantidade de inputs; } \\
& s=\text { quantidade de outputs; } \\
& \mathrm{n}=\text { quantidade de DMU's; } \\
& \mathrm{y}_{\mathrm{jk}}=\text { quantidade de output } \mathrm{j} \text { para a } \mathrm{DMU} \mathrm{k}_{\mathrm{i}} \\
& x_{\mathrm{ik}}=\text { quantidade de input i para } \mathrm{a} \mathrm{DMU}_{\mathrm{k}} \text {; } \\
& u_{j}=\text { peso referente ao output } j ; \\
& v_{i}=\text { peso referente ao input } i \\
& y_{\mathrm{j} 0}=\text { quantidade de output } \mathrm{j} \text { para a } \mathrm{DMU}_{0} \text { (DMU observada); } \\
& \mathrm{x}_{\mathrm{i} 0}=\text { quantidade de input } \mathrm{i} \text { para } \mathrm{a} \mathrm{DMU} \text {. }
\end{aligned}
$$

Nesse sentido, por meio da utilização do modelo (1) se calculou a eficiência das DMU's, e, com isso foi construída a fronteira de eficiência padrão, as quais podem ser referência (benchmarks) das melhores práticas às que estiverem sob a fronteira (GOMES et al., 2012; MEZA et al., 2007). Como o DEA é muito benevolente com as DMU's em sua eficiência padrão foram utilizadas, ainda, as eficiências invertida, a composta e a composta normalizada (Composta*). Isso foi necessário para determinar uma ordem prioritária de eficiência e afastar unidades de falsa eficiência (LETA et al., 2005; BIONDI NETO et al., 2007; MEZA et al., 2007; GOMES et al., 2012). A eficiência composta é o resultado obtido entre a eficiência clássica (padrão) e o complemento da eficiência em relação à fronteira invertida, tal como visto na equação 2 (PIMENTA e MELLO, 2005; MEZA et al. 2007).

$$
\text { Eficiência composta }=\frac{\text { Eficiência padrão }+(1-\text { Eficiência invertida })}{2}
$$

A eficiência composta* (denominada composta normalizada) é obtida por meio da divisão do valor da eficiência composta pelo maior valor entre todos os valores de eficiência composta encontrada entre as DMU's (PIMENTA et al., 2005) tal como visto na equação 3.

$$
\text { Eficiência composta* }=\frac{\text { Eficiência composta }}{\text { Máxima eficiência composta }}
$$


A classificação das DMU's seguiu o disposto no quadro 1. Assim foi considerada eficiente a que atingiu o valor de 1,000. Para fins de benchmarks seguiu-se a eficiência padrão, inclusive para verificação da minimização de insumos. Ainda, cabe destacar que as DMU's mais eficientes foram aquelas que utilizaram menos recursos na produção de seus produtos, alcançando fronteiras virtuais de eficiência. Utilizou-se do termo ano e não safra tendo em vista que os empreendimentos implantados em Mato Grosso do Sul (CentroSul), a safra se inicia em abril e vai até dezembro do mesmo ano (com raras exceções).

Quadro 1: Classificação das unidades tomadoras de decisão.

\begin{tabular}{|l|l|}
\hline Classificação & Valor da eficiência \\
\hline Eficiente & $=1,000$ \\
\hline Alta eficiência & $\geq 0,900 \mathrm{e}<1,000$ \\
\hline Média eficiência & $\geq 0,600 \mathrm{e}<0,900$ \\
\hline Baixa eficiência & $<0,600$ \\
\hline
\end{tabular}

Fonte: adaptado de Giacomello et al. (2014).

Nesse estudo utilizaram-se informações obtidas a nível municipal onde se encontram instaladas as unidades sucroalcooleiras no estado de MS. Foram utilizados valores de cana-de-açúcar e de açúcar em toneladas, e de etanol em metros cúbicos. De qualquer modo, para a presente pesquisa, as unidades tomadoras de decisão (DMU) consideradas nesses casos foram referidas aos municípios, com a soma das produções das usinas instaladas nos mesmos.

Pondera-se que se utilizou de tentativas e tratativas para obtenção de dados primários nas próprias usinas, no entanto, foram frustradas. O problema foi resolvido com a utilização de dados secundários constantes em organismos oficiais, tais como: Instituto Brasileiro de Geografia e Estatística (IBGE, 2017) e União da Indústria de Cana-de-Açúcar (UNICA, 2018).

\section{RESULTADOS E DISCUSSÃO}

No ano de 2005 foram produzidos $495.591 \mathrm{~m}^{3}$, ou 495.591 mil litros de etanol em MS, o que resultou numa média de $6.442 .683 \mathrm{~m}^{3}$ de vinhaça. A vinhaça é um subproduto do etanol que pode causar sérios danos ao meio ambiente, pois, calcula-se entre dez e quinze litros desse resíduo para cada litro de etanol produzido (NOGUEIRA et al., 2013; PIATTO et al., 2017).

À medida que foram aumentando as instalações das indústrias produtoras de açúcar, etanol e energia, foi crescendo, também, a produção de resíduos. Para o ano de 2015 as quantidades de vinhaça são muito mais altas, em razão da instalação de várias outras indústrias no estado de MS. Foram produzidas, nesse ano, cerca de 34 bilhões de litros, que foram estocados ou utilizados para fertirrigação nas áreas próximas das unidades industriais, em razão da dificuldade de distribuição em longas distâncias. Isso gera forte odor na área urbana, pois as indústrias, geralmente, são instaladas próximas às cidades.

Destaca-se que a vinhaça é 100 vezes mais poluente que o esgoto doméstico (SILVA et al., 2007), o que requer redobrada atenção ao se utilizar a mesma na fertirrigação na intenção de minimizar a contaminação do lençol freático (COELHO et al., 2007). O mesmo ocorre com a produção de torta de filtro que acompanha a produção do açúcar, e isso requer cuidados.

Conforme tabela 1, a média de cana-de-açúcar processada no ano 2000 foi de 815.115 t, a menor 
293.441 t e a maior 1.227.167 t. Três das DMU's só produziram etanol, sendo assim a produção máxima de açúcar foi de 68.263 t no período. Observam-se as diferenças entre produção mínima e máxima, explicitando a heterogeneidade da produção entre as usinas. A produção de açúcar e/ou etanol é uma decisão que envolve os mercados interno e externo, necessitando de muita experiência na hora de decidir. 0 desviopadrão de 61,01\% (etanol) e 102,28\% (açúcar) corrobora com essa afirmação, mostrando a heterogeneidade de decisões.

Tabela 1: Estatística descritiva das DMU's nos anos de 2000, 2005, 2010 e 2015 em MS, com volume mínimo, máximo, e média de cana-de-açúcar, açúcar em toneladas e etanol em $\mathrm{m}^{3}$, bem como os desvios padrão e coeficiente de variação.

\begin{tabular}{|c|c|c|c|c|c|c|}
\hline \multirow{2}{*}{ Produto } & \multirow[t]{2}{*}{ Ano } & \multicolumn{5}{|c|}{ Estatística descritiva } \\
\hline & & Mínimo & Máximo & Média & Desvio padrão & Coef. de Variação (\%) \\
\hline \multirow[t]{4}{*}{ Cana-de-açúcar (t) } & 2000 & 293.441 & 1.227 .167 & 815.115 & 300.429 & 36,86 \\
\hline & 2005 & 628.131 & 1.434 .205 & 1.004 .213 & 314.047 & 31,27 \\
\hline & 2010 & 598.514 & 9.040 .193 & 1.969 .206 & 2.010 .382 & 102,09 \\
\hline & 2015 & 114.009 & 8.313 .308 & 2.477 .641 & 2.028 .174 & 81,86 \\
\hline \multirow[t]{4}{*}{ Açúcar (t) } & 2000 & - & 68.263 & 28.959 & 29.619 & 102,28 \\
\hline & 2005 & - & 137.682 & 50.107 & 54.069 & 107,91 \\
\hline & 2010 & - & 547.291 & 78.150 & 136.457 & 174,61 \\
\hline & 2015 & - & 328.256 & 70.209 & 107.253 & 152,76 \\
\hline \multirow[t]{4}{*}{ Etanol $\left(\mathrm{m}^{3}\right)$} & 2000 & 16.684 & 86.569 & 39.348 & 24.006 & 61,01 \\
\hline & 2005 & 27.906 & 79.132 & 55.066 & 15.864 & 28,81 \\
\hline & 2010 & 36.762 & 341.985 & 108.600 & 71.958 & 66,26 \\
\hline & 2015 & 6.040 & 383.696 & 145.050 & 112.372 & 77,47 \\
\hline
\end{tabular}

Do ano de 2000 para o ano de 2005 após novo ciclo de expansão do setor canavieiro, houve variação na produção média de cana-de-açúcar, açúcar e etanol, em 23,2\%, 73,03\% e 39,95\% respectivamente. Interessante notar que após 2003 com a ampliação de fabricação dos motores flex fuel se esperava um aumento bem maior na produção de etanol e não de açúcar. É preciso observar que em 2005 são nove as DMU's, das quais, quatro só produzem etanol. O coeficiente de variação na produção do açúcar foi de 107,21\%, até compreensível tendo em vista que várias DMU's não o produzem.

Após 2008 implantaram-se várias usinas de açúcar e álcool no estado de MS, de modo que, em 2010 as DMU's passaram a dezessete, das quais, oito só produziam etanol. Assim, a média de utilização de canade-açúcar aumentou (96\%) atingindo 1.969.206 t, em relação a 2005. A média de produção de açúcar e etanol, também, aumentou em $55,97 \%$ e $97,22 \%$, respectivamente.

O desvio padrão da produção de cana-de-açúcar foi de mais de dois milhões. Isso se deveu ao fato que a DMU Rio Brilhante possuía três usinas instaladas, obtendo tamanho volume, enquanto outras DMU's são apenas destilarias de álcool, com volumes bem inferiores. No entanto, se verifica que o maior coeficiente de variação ocorreu na produção de açúcar, em razão de várias unidades instaladas produzirem apenas etanol. As usinas de Brasilândia e Sidrolândia começaram a apresentar problemas nos anos iniciais do século XXI, parando o processamento após o ano de 2010.

O valor mínimo de cana-de-açúcar processada (em 2015) foi da DMU Naviraí, que vinha apresentando quadro deficitário. O valor máximo é da DMU Rio Brilhante, que conta com três usinas de açúcar e álcool instaladas no município. Esses fatos evidenciam o valor alto do desvio padrão na produção de cana-de-açúcar no período. A tabela 2 apresenta os resultados gerados pela DEA em termos de eficiência 
padrão. As DMU's Sonora, Brasilândia, Maracaju e Rio Brilhante apresentam-se eficientes pelo padrão (2000), no entanto na classificação da composta normalizada (composta*) somente Sonora foi eficiente e Brasilândia obteve alta eficiência. As demais se encontram na faixa de média eficiência.

Em 2005 três DMU's foram eficientes: Aparecida do Taboado (produz etanol), Rio Brilhante e Sonora (produção mista). Interessante notar que a usina de Sonora, uma planta fabril instalada muito antes, consegue ser eficiente composta normalizada (novamente) em detrimento de outras mais modernas. As DMU's com alta eficiência (composta*) foram Aparecida do Taboado, Nova Alvorada do Sul e Nova Andradina. As demais DMU's se encontram na faixa de média eficiência, no entanto é preciso evidenciar que nenhuma das DMU's em análise apresentou baixa eficiência.

Tabela 2: DMU's eficientes (padrão) nos anos de 2000, 2005, 2010 e 2015, bem como a eficiente composta normalizada pelo DEA_CCR (inputs) em MS.

\begin{tabular}{|l|l|l|l|l|}
\hline \multirow{2}{*}{\multicolumn{1}{|c|}{ DMU's }} & \multicolumn{2}{c|}{ Eficiências } \\
\cline { 2 - 5 } & \multicolumn{1}{c|}{$\mathbf{2 0 0 0}$} & \multicolumn{2}{c|}{$\mathbf{2 0 1 0}$} & $\mathbf{2 0 1 5}$ \\
\hline Sonora & $1,000^{*}$ & $1,000^{*}$ & 1,000 & - \\
\hline Brasilândia & 1,000 & - & - & - \\
\hline Maracaju & 1,000 & - & 1,000 & 1,000 \\
\hline Rio Brilhante & 1,000 & 1,000 & - & - \\
\hline Aparecida do Taboado & - & 1,000 & - & - \\
\hline Chapadão do Sul & - & - & $1,000^{*}$ & - \\
\hline Costa Rica & - & - & - & $1,000^{*}$ \\
\hline Angélica & - & - & - & 1,000 \\
\hline Caarapó & - & - & - & 1,000 \\
\hline
\end{tabular}

Em 2010 são eficientes (padrão): Sonora, Maracaju e Chapadão do Sul que é a única eficiente (composta*). No entanto em 2015 integram a lista de eficientes (padrão) Angélica, Costa Rica, Caarapó e Maracaju. Na eficiência composta normalizada aparece Costa Rica (Tabela 2). Enquanto a eficiência padrão evidencia as melhores práticas gerenciais quando verificado a eficiência invertida aparecem as DMU's de piores práticas, conforme tabela 3 .

Tabela 3: DMU's eficientes (invertida) nos anos de 2000, 2005, 2010 e 2015, bem como a eficiente (invertida) pela composta normalizada no DEA_CCR (inputs) em MS.

\begin{tabular}{|c|c|c|c|c|}
\hline \multirow[b]{2}{*}{ DMU's } & \multicolumn{4}{|c|}{ Eficiências } \\
\hline & 2000 & 2005 & 2010 & 2015 \\
\hline Rio Brilhante & 1,000 & 1,000 & - & - \\
\hline Nova Alvorada do Sul & $1,000^{*}$ & - & - & - \\
\hline Maracaju & - & 1,000 & 1,000 & 1,000 \\
\hline Brasilândia & - & 1,000 & - & - \\
\hline Sidrolândia & - & $1,000 *$ & 1,000 & - \\
\hline Batayporã & - & - & $1,000 *$ & - \\
\hline Naviraí & - & - & - & 1,000 \\
\hline Fátima do Sul & - & - & - & 1,000 \\
\hline Dourados & - & - & - & $1,000 *$ \\
\hline
\end{tabular}

Na eficiência invertida são eficientes as empresas com piores práticas. Verifica-se que em 2000 estão as DMU's Rio Brilhante e Nova Alvorada do Sul. A primeira é falsa eficiente, pois aparece como eficiente tanto nas melhores quanto nas piores práticas (Tabelas 2 e 3). A segunda é a menos eficiente nesse ano. Novamente em 2005, a DMU Rio Brilhante se apresenta como falso eficiente, pois, foi eficiente tanto na eficiência padrão como na invertida, mas nesse ano foi benchmark para Maracaju, Naviraí e Sidrolândia. 
A DMU Nova Alvorada do Sul também se tornou eficiente nas piores práticas em 2005 ( envertida $_{\text {in }} 1$ ), o que parece até coerente, tendo em vista que pouco tempo depois foi desativada. As DMU'S que ficaram nas primeiras colocações pela eficiência invertida, com algumas exceções pouco tempo depois, deixaram de processar cana-de-açúcar.

No ano de 2015 as DMU's Brasilândia e Sidrolândia não processaram cana-de-açúcar. A DMU Anaurilândia que iniciou atividades em 2012 ficou pouco tempo em operação e nem chegou a operar em 2015. A DMU Naviraí foi diminuindo paulatinamente a produção e, em 2015 foi a que menos processou canade-açúcar. Na sequência se demonstram as DMU's que foram benchmarks para as ineficientes em cada ano (Tabela 4).

Cabe destacar que no ano de 2000 a DMU Brasilândia é benchmark para as DMU's Nova Alvorada do Sul, Nova Andradina e Sidrolândia. A DMU Maracaju é referência para Naviraí, e ainda a DMU Sonora o é para Naviraí e Sidrolândia. Considerando esses resultados, com base no SIAD e a título de exemplo, a DMU Naviraí para obter a eficiência deveria usar o peso de 1,212 multiplicado pelos insumos da DMU Maracaju mais 0,086 multiplicado pelos insumos da DMU Sonora. Ou seja, nesse ano a DMU Naviraí processou 1.007.021 t de cana-de-açúcar, mas para tornar-se eficiente deveria ter processado 998.180 t. A mesma situação deve ser efetuada nas demais DMU's.

Tabela 4: DMU's eficientes que servem de benchmark (referência) para as ineficientes nos anos de 2000, 2005, 2010 e 2015 no estado de MS.

\begin{tabular}{|l|l|l|l|l|}
\hline \multicolumn{1}{|c|}{ DMU'S Benchmarks/ano } & \multicolumn{1}{c|}{$\mathbf{2 0 0 0}$} & $\mathbf{2 0 0 5}$ & $\mathbf{2 0 1 0}$ & $\mathbf{2 0 1 5}$ \\
\hline Brasilândia & $\mathrm{X}$ & & \\
\hline Sonora & $\mathrm{X}$ & $\mathrm{X}$ & $\mathrm{X}$ & \\
\hline Maracaju & $\mathrm{X}$ & & $\mathrm{X}$ & \\
\hline Aparecida do Taboado & & $\mathrm{X}$ & & \\
\hline Rio Brilhante & & $\mathrm{X}$ & & \\
\hline Chapadão do Sul & & & $\mathrm{X}$ & \\
\hline Angélica & & & & \\
\hline Costa Rica & & & & $\mathrm{X}$ \\
\hline
\end{tabular}

Em 2005 A DMU Aparecida do Taboado foi benchmark para Brasilândia, Nova Alvorada do Sul e Nova Andradina. Rio Brilhante, mesmo sendo falso eficiente, foi benchmark para as DMU's Maracaju, Naviraí e Sidrolândia e, a DMU Sonora o foi para Maracaju, Naviraí e Sidrolândia. Em 2010, constam Chapadão do Sul (produção de etanol), Sonora e Maracaju (produção mista) como benchmark das demais, como segue: Chapadão do Sul é referência para: Batayporã, Brasilândia, Dourados, Iguatemi, Nova Alvorada do Sul, Nova Andradina, Ponta Porã, Sidrolândia e Vicentina. Maracaju é para: Angélica, Aparecida do Taboado, Caarapó, Naviraí e Rio Brilhante. Sonora é para: Angélica, Aparecida do Taboado, Caarapó, Dourados, Naviraí, Rio Brilhante e Sidrolândia.

No ano de 2015 quatro DMU's foram 100\% eficientes, sendo: Costa Rica (produção etanol), Angélica, Caarapó e Maracaju (produção mista). No entanto, somente Angélica e Costa Rica foram benchmarks para as demais. Enquanto a DMU angélica foi benchmark para Aparecida do Taboado, Dourados, Ivinhema, Naviraí, Rio Brilhante e Sonora, a DMU Costa Rica se mostrou referência para todas as outras DMU's em atividade (excluindo Angélica). 
A DMU Sonora (eficiente em 2000 e 2005) é da mesorregião Centro Norte de MS, na divisa com Mato Grosso, Chapadão do Sul (Paraíso das Águas) (eficiente em 2010), e Costa Rica (eficiente em 2015) estão na mesorregião Leste de MS. A maioria das usinas do estado de MS está instalada na mesorregião Sudoeste. No entanto as mais eficientes estão mais próximas ao estado de São Paulo, Goiás, Minas Gerais e Mato Grosso.

Para fins de comparação dos anos analisados, a tabela 5 apresenta as médias das eficiências em cada ano. Isso é importante para verificar como se comportou as eficiências ao longo do tempo. No ano de 2000 havia somente oito DMU's no estado de MS, as quais apresentaram média de alta eficiência na utilização do insumo cana-de-açúcar. Por outro lado, apresentaram, também, a média mais baixa de eficiência invertida, ou seja, esse período mostra a mais baixa média de ineficiência entre todos os períodos analisados $(0,872)$.

No ano de 2005 as DMU's apresentaram médias mais altas, tanto na eficiência padrão como na eficiência invertida, denotando melhores práticas gerenciais, bem como, piores práticas gerenciais. Em 2010 houve uma diminuição da eficiência padrão, talvez, em decorrência da instalação de várias unidades no estado de MS. Esse período representou um dos melhores momentos do setor, com fusões e a entrada de capital estrangeiro aplicado.

Tabela 5: Médias das eficiências das DMU's nos anos de 2000, 2005, 2010 e 2015 em MS.

\begin{tabular}{|l|l|l|l|l|}
\hline \multirow{2}{*}{ Anos analisados } & \multicolumn{3}{c|}{ Composta } & \multicolumn{1}{c|}{ Composta* } \\
\cline { 2 - 5 } & \multicolumn{1}{|c|}{ Padrão } & \multicolumn{1}{c|}{ Invertida } & 0,821 \\
\hline 2000 & 0,948 & 0,872 & 0,538 & 0,889 \\
\hline 2005 & 0,956 & 0,955 & 0,500 & 0,822 \\
\hline 2010 & 0,918 & 0,900 & 0,509 & 0,817 \\
\hline 2015 & 0,908 & 0,935 & 0,487 & \\
\hline
\end{tabular}

Em 2015, o que se observa é uma piora substantiva na média da eficiência padrão do setor devido, em parte, pelas crises enfrentadas pelo setor, com várias unidades passando por dificuldades e encerrando as suas operações. As piores práticas obtiveram média mais alta do que o ano de 2010, com algumas empresas sendo salvas pela produção de energia, que não foi objeto dessa análise.

\section{CONCLUSÕES}

Os resultados mostraram que as usinas de açúcar e álcool instaladas no estado de MS apresentaram de médias a altas eficiências no uso do recurso cana-de-açúcar que processaram. Observou-se que em nenhum período analisado, alguma das DMU's apresentou baixa eficiência. Notadamente, as DMU's eficientes são referências de melhores práticas às que se encontram abaixo da fronteira de eficiência. Assim, foi possível verificar, com base nos dados utilizados, que as DMU's estão conseguindo manter-se em média eficiência nos períodos analisados. Percebe-se, no entanto, que os produtos obtidos com o esmagamento da cana-de-açúcar são commodities e, portanto, estão sujeitos às oscilações do mercado.

As DMU's não têm controle sobre os preços desses produtos estando, assim, sujeitos a alterações diárias. Nesse sentido, para as DMU's resta somente a opção de controlar os recursos utilizados no processo de produção. Os resultados apresentados, ainda, evidenciaram que as DMU's com as piores práticas (eficientes pela eficiência invertida), coincidentemente, estavam paralisando as suas atividades, o que reforça a utilização dessa técnica como um dos requisitos para a busca de melhores práticas gerenciais para 
sobrevivência no mercado.

As unidades industriais são, geralmente, instaladas próximo aos centros urbanos. Os resíduos líquidos são armazenados e utilizados nas proximidades das unidades gerando forte exalação de odores. Como é o caso da vinhaça utilizada para fertirrigação, lançada nas proximidades das unidades industriais e, consequentemente, dos municípios. A produção de vinhaça é enorme e, dependendo da sua utilização no solo, pode ocasionar poluição dos lençóis freáticos. Por outro lado, é preciso urgentemente, pesquisas que identifiquem os impactos diretos e indiretos conjuntos da concentração das unidades industriais potencialmente poluidoras sobre o estado de Mato Grosso do Sul.

\section{REFERÊNCIAS}

AHMAD, N.; SINHA, D. K.; SINGH, K. M.. Economic analysis of growth, instability and resource use efficiency of sugarcane cultivation in India: an econometric approach. Indian Journal of Economics and Development, Adyar, v.6, n.4, p.1-10, 2018.

BANKER, R. D.; CHARNES, A.; COOPER, W. W.. Some Models for Estimating Technical and Scale Inefficiencies in Data Envelopment Analysis. Management Science, Maryland, v.30, n.9, p.1078-1092, 1984. DOI:

https://doi.org/10.1287/mnsc.30.9.1078

BIONDI NETO, L.; COELHO, P. H. G.; MELLO, J. C. C. B. S; MEZA, L.. Self-organizing maps for classification of the Rio de Janeiro state cities based on electrical energy consumption. In: INTERNATIONAL CONFERENCE ON ENTERPRISE INFORMATION SYSTEMS, 9. Anais. Funchal: ICEIS, 2007. p.447-450.

BRUNOZI JÚNIOR, A. C.; ABRANTES, L. A.; GOMES, A. P.; GONÇALVES, R. M. L.. Eficiência produtiva e análise econômica e financeira de usinas de cana-de-açúcar do estado de São Paulo. Revista Ambiente Contábil, Natal, v.4, n.2, p.74-92, 2012.

CASADO, F. L.. Análise envoltória de dados: conceitos, metodologia e estudo da arte na educação superior. Revista Sociais e Humanas, Santa Maria, v.20, n.1, p.59-71, 2007.

CHARNES, A.; COOPER, W. W.; LEWIN, A. Y.; SEIFORD, L. M.. Data Envelopment Analysis: Theory, Methodology, and Application. Boston: Kluwer Academic Publishers, 1994. DOI: https://doi.org/10.1007/978-94-011-0637-5.

CHARNES, A.; COOPER, W. W.; RHODES, E.. Measuring the efficiency of decision-making units. European Journal of Operational Research, v.2, n.6, p.429-444, 1978. DOI: https://doi.org/10.1016/0377-2217(78)90138-8

COELHO, S. T.; GUARDABASSI, P. M.; LORA, B. A.; MONTEIRO, M. B. C. A.; GORREN, R.. A sustentabilidade da expansão da cultura canavieira. Cadernos Técnicos da Associação Nacional de Transportes Públicos, São Paulo, v.6, p.146-152, 2007.

GIACOMELLO, C. P.; OLIVEIRA, R. L.. Análise envoltória de dados (DEA): uma proposta para avaliação de desempenho de unidades acadêmicas de uma universidade. Revista GUAL, Florianópolis, v.7, n.2, p.130-151, 2014. DOI:

\section{http://dx.doi.org/10.5007/1983-4535.2014v7n2p130}

GOMES, E. G.; MELLO, J. C. C. B. S.; MEZA, L.; SILVEIRA, J. Q.; BIONDI NETO, L.; ABREU, U. G. P.. Some Remarks about Negative Efficiencies in DEA Models. In: HOLTZMAN, Y.. Advanced Topics in Applied Operations Management. Londres: In Tech, 2012. p.113-132.

IBGE. Instituto Brasileiro de Geografia e Estatística. Sistema IBGE de Recuperação Automática. Banco de dados agregados. Rio de Janeiro: SIDRA, 2017.

LESTARI, E. K.; FAUZI, A.; HUTAGAOL, M. P.; HIDAYAT, A. Analysis of Sugarcane Farming in the Sugar Mill District Semboro Jember, Indonesia: A Data Envelopment Analysis Application. International Journal of Sciences: Basic and Applied Research, Amman, v.25, n.2, p.157-171, 2016.

LETA, F. R.; MELLO, J. C. C. B. S.; GOMES, E. G.; MEZA, L.. Métodos de melhora de ordenação em DEA aplicados à avaliação estática de tornos mecânicos. Investigação Operacional, Lisboa, v.25, n.2, p.229-242, 2005.

MACEDO, M. A. S.; STEFFANELLO, M.; OLIVEIRA, C. A.. Eficiência combinada dos fatores de produção: aplicação de Análise Envoltória de Dados (DEA) à produção leiteira. Custos e Agronegócio, Recife, v.3, n.2, p. 59-86, 2007.

MEZA, L. A; BIONDI NETO, L.; MELLO, J. C. C. B. S.; GOMES, E. G.. ISYDS - Integrated System for Decision Support (SIAD Sistema Integrado de Apoio a Decisão): a software package for data envelopment analysis model. Pesquisa Operacional, Rio de Janeiro, v.25, n.3, p.493-503, 2005

MEZA, L. A.; MELLO, J. C. C. B. S.; GOMES, E. G.; FERNANDES, A. J. S.. Seleção de variáveis em DEA aplicada a uma análise do mercado de energia eléctrica. Investigação Operacional, Lisboa, v.27, n.1, p.21-36, 2007.

NOGUEIRA, M. A. F. S.; GARCIA, M. S.. Gestão dos resíduos do setor industrial sucroenergético: estudo de caso de uma usina no município de Rio Brilhante, Mato Grosso do Sul. Revista Eletrônica em Gestão, Educação e Tecnologia Ambiental, Santa Maria, v.17, n.17, p.3275-3283, 2013. DOI: http://dx.doi.org/10.5902/2236117010444

PIATTO, M.; COSTA JUNIOR, C.; SILVEIRA, N. V. B.. Nota metodológica setor agropecuário. Piracicaba: Instituto de Manejo e Certificação Florestal e Agrícola, 2017. 
PIMENTA, H. L. N.; MELLO, J. C. C. B. S.. Modelo DEA-SAVAGE para análise de eficiência do parque de refino brasileiro. In: Simpósio Brasileiro de Pesquisa Operacional, 27. Anais. Gramado, 2005. p.387-397.

SALGADO JUNIOR, A. P.; BONACIM, C. A. G.; PACAGNELLA JUNIOR, A. C.. Aplicação da análise envoltória de dados (DEA) para avaliação de eficiência de usinas de açúcar e álcool da região nordeste do estado de São Paulo.

Organizações Rurais \& Agroindustriais, Lavras, v.11, n.3, p.494-513, 2009.

SALGADO JUNIOR, A. P.; CARLUCCI, F. V.; NOVI, J. C.. Aplicação da Análise Envoltória de Dados (AED) na avaliação da eficiência operacional relativa entre usinas de cana-deaçúcar no território brasileiro. Engenharia Agrícola, Jaboticabal, v.34, n.5, p.826-843, 2014. DOI:
http://dx.doi.org/10.1590/S0100-69162014000500003

SILVA, M. A. S.; GRIEBELER, N. P.; BORGES, L. C.. Uso de vinhaça e impactos nas propriedades do solo e lençol freático. Revista Brasileira de Engenharia Agrícola e Ambiental, Campina Grande, v.11, n.1, p.108-114, 2007. DOI: http://dx.doi.org/10.1590/S1415-43662007000100014

SOUZA, N. J.. Desenvolvimento econômico. 5 ed. São Paulo: Atlas, 2009.

UNICA. União da Indústria da Cana-de-Açúcar. UNICADATA. Produção. São Paulo: UNICA, 2018.

WAGNER, J. M.; SHIMSHAK, D. G.. Stepwise selection of variables in data envelopment analysis: Procedures and managerial perspectives. European Journal of Operational Research, Amsterdam, v.180, n.1, p.57-67, 2007.

A CBPC - Companhia Brasileira de Produção Científica (CNPJ: 11.221.422/0001-03) detém os direitos materiais desta publicação. Os direitos referem-se à publicação do trabalho em qualquer parte do mundo, incluindo os direitos às renovações, expansões e disseminações da contribuição, bem como outros direitos subsidiários. Todos os trabalhos publicados eletronicamente poderão posteriormente ser publicados em coletâneas impressas sob coordenação da Sustenere Publishing, da Companhia Brasileira de Produção Científica e seus parceiros autorizados. Os (as) autores (as) preservam os direitos autorais, mas não têm permissão para a publicação da contribuição em outro meio, impresso ou digital, em português ou em tradução. 